\title{
Acute Myocarditis
}

National Cancer Institute

\section{Source}

National Cancer Institute. Acute Myocarditis. NCI Thesaurus. Code C35206.

The sudden onset of inflammation of heart muscle with myocellular necrosis; this is generally secondary to an infectious cause, and patients often have a recent history of a flu-like illness. 